\title{
Microwave-assisted synthesis of silver nanoparticles from Origanum majorana and Citrus sinensis leaf and their antibacterial activity: a green chemistry approach
}

\author{
Darshan Singh" ${ }^{*}$, Deepti Rawat ${ }^{2}$ and Isha $^{3}$
}

\begin{abstract}
Background: Silver nanoparticles (SNPs) play important role in the field of optics and electronics and also as a novel antibacterial agents. Here, we report a simple and green method for the biosynthesis of SNPs using aqueous leaf extract of Origanum majorana and Citrus sinensis as a novel bio source of cost-effective, non-hazardous reducing, and stabilizing agents. A $3 \mathrm{mM}$ solution of silver nitrate was prepared. Five milliliter aqueous leaf extract was slowly added to $20 \mathrm{ml}$ silver salt solution ( $3 \mathrm{mM}$ ) with constant stirring. No noticeable color change was observed. The solution was then heated in domestic microwave for variable time intervals. The intense brown colored solution was obtained on 1 min heating with $O$. majorana and 5 min heating with C. sinensis extract. The intense brown color indicated the formation of SNPs. The antibacterial activity of synthesized SNPs was investigated.
\end{abstract}

Results: SNPs were rapidly synthesized using aqueous leaf extract of $O$. majorana and $C$. sinensis on microwave irradiation. Formation of SNPs was confirmed by the change in color from yellowish green to brown and absorption maximum around $\sim 420$ and $410 \mathrm{~nm}$ due to surface plasmon resonance of SNPs. They were also characterized by other physical-chemical techniques like Fourier transform infrared spectroscopy (FT-IR), scanning electron microscope coupled with X-ray energy dispersive spectroscopy, and high-resolution transmission electron microscopy. TEM analysis showed the presence of feather-shaped NPs in O. majorana and spherical as well as cubical-shaped NPs in C. sinensis-mediated SNPs. The synthesized SNPs showed significance antibacterial activity against two human pathogenic strains.

Conclusion: The SNPs were synthesized using leaf extract of plants. This synthesis method is nontoxic, eco-friendly, and a low-cost technology for the large-scale production. The SNPs can be used as a new generation of antibacterial agents.

Keywords: Green synthesis, Origanum majorana, Citrus sinensis, Antibacterial activity

\section{Background}

The field of nanotechnology is one of the most dynamic areas of research because of their unique physicochemical characteristics such as catalytic activity, optical, electronic, and magnetic properties (Krolikowska et al. 2003; Catauro et al. 2004; Crabtree et al. 2003; Sharma et al.

\footnotetext{
*Correspondence: darshnachem2004@gmail.com

${ }^{1}$ Department of Chemistry, Daulat Ram College, University of Delhi, Delhi 110007, India

Full list of author information is available at the end of the article
}

2009). Silver has been employed extensively for various biomedical purposes since ancient time. The interest in silver nanoparticles (SNPs) has gained prominence owing to its excellent plasmonic activity, electromagnetic, optical and catalytic properties, and bacteriostatic and bactericidal effects along with antiproliferative effects compared with other metal nanoparticles. Its wide application in dentistry, clothing, catalysis, mirrors, optics, photography, electronics, and in the food packaging industry has tremendously increased its market value
Springer Open 
(Navaladian et al. 2007; Starowicz et al. 2006; Easu et al. 2010; Raveendran et al. 2003). The large surface area of SNPs allows them to interact better with microorganisms and, thus, impart good antibacterial activity even at lower concentrations. When SNPs enter inside a pathogen, the particle releases silver ions, thereby killing it. Several mechanisms have been suggested to explain the activity of SNPs on bacteria such as: (a) inactivation of respiratory chain, (b) disruption of cell membrane and leakage of its cellular contents, (c) binding to functional group of proteins causing protein denaturation and cell death, (d) blocking of DNA replication, and (e) denaturation of enzymes which transport nutrients across bacterial cell membrane (Kumar et al. 2004). The synthesis of nanoscaled silver is dominated by physical and chemical processes that include thermal evaporation, chemical vapor deposition, pulsed laser deposition, sol-gel, sonochemical, hydrothermal, etc. (Raveendran et al. 2003; Sanghi et al. 2009; Xin et al. 2010; Huang et al. 2008; Liu and Lin 2004; Vorobyova et al. 1999; Bae et al. 2002; Mandal et al. 2000; Basavaraja et al. 2008; Kowshik et al. 2003). All these methods require high energy and involve the use of toxic chemicals. To mitigate these, problems greener approaches are being explored by various scientists. One such promising method is the biosynthesis of nanoparticles using plant-based extracts (Keki et al. 2000; Jha and Prasad 2010; Yu 2007). In fact, biosynthesis approach has been considered the most effective in the synthesis of metal nanoparticles. Microwave irradiation (MWI) is considered to be highly effective technology and is widely used in the synthesis of nanoparticles because of more homogeneous heating process and can speed up the reaction rate by orders of magnitude compared with conventional heating (Bahadur et al. 2011; Jiang et al. 2013). Microwave synthesis has been increasingly applied in various fields of chemistry and materials science (Singh et al. 2012; Tanan and Saengsuwan 2014) due to its generally simple, rapid volumetric heating, and the consequent dramatic increase in reaction rate. While significant work has been reported on the use of several plant-based extracts to prepare various metal nanoparticles (He et al. 2007; Sivakumar et al. 2012; Song and Kim 2009; Geethalakshmi and Sarada 2010), but there is no report in the literature for microwave-assisted biosynthesis of SNPs from "Origanum majorana" and Citrus sinensis leaf (Fig. 1).

In this article, we report a simple, robust, and ecofriendly method for the biosynthesis of SNPs using an aqueous leaf extract of "O. majorana" and "C. sinensis" as a bio-reductant and stabilizer. O. majorana is also called sweet marjoram. This plant is native to North Africa, Turkey, and SW Asia, extensively cultivated in India. Dried marjoram is extremely useful in industrial food processing and is used, together with thyme, in spice mixtures for the production of sausages. It is commonly called marwa in Hindi language. Its leaf contains protein, terpineol, sabinene hydrate (cis and trans) linalool oil, and pentosans. C. sinensis commonly called orange has high levels of glucose and ascorbic acid (vitamin C). Besides this, it also contains aldehyde such as n-octanal, 2,6-dimethyl-2,6-octadiene-1,8-dial, 4-isopropenyl-1-methyl-1,2-cyclohexanedial and alcohols like 1-octanol, $\beta$-linalool, and 1-nonanol. Further these biologically synthesized SNPs were found highly toxic against different pathogenic bacteria.

\section{Methods}

\section{Materials}

Silver nitrate $\left(\mathrm{AgNO}_{3}, 99.995 \%\right)$ was purchased from Merck, India. $\mathrm{NaCl}, \mathrm{NaOH}$, yeast, and Tryptone were purchased from Spectrochem, India. All the reagents were of analytical grade. The O. majorana and C. sinensis leaf were collected from botanical garden of Daulat Ram College, University of Delhi, India. These were
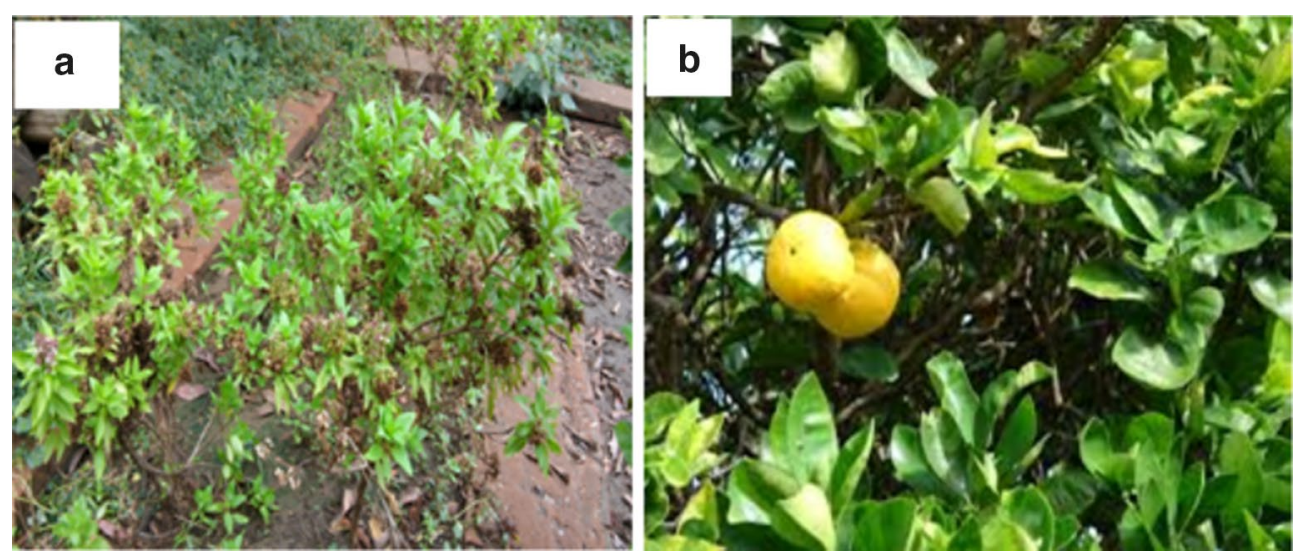

Fig. 1 a Origanum majorana and $\mathbf{b}$ Citrus sinensis plant 
washed with deionized water before use. All glassware was washed and rinsed with deionized water, followed by subsequent drying.

\section{Preparation of plant leaf extract}

The collected leaf were washed several times with deionized water to remove the dust particles and then sundried to remove the residual moisture. The dried leaf were cut into small pieces and boiled in $100 \mathrm{ml}$ deionized water for 10-15 min. After boiling, the color of the aqueous solution changed from colorless to yellowish green color. The aqueous leaf extract was separated by filtration with in Whatman No. 1 filter paper and then centrifuged at $1200 \mathrm{rpm}$ for $5 \mathrm{~min}$ to remove heavy biomaterials. The prepared leaf extract was stored at room temperature to be used for biosynthesis of SNPs from silver nitrate.

\section{Synthesis of silver nanoparticles}

Silver nitrate solution of known strength ( $3 \mathrm{mM}$ ) was prepared in $100 \mathrm{ml}$ deionized water. $5 \mathrm{ml}$ aqueous extract of leaf was slowly added to $20 \mathrm{ml}$ silver salt solution ( $3 \mathrm{mM}$ ) with constant stirring. No noticeable color change was observed. The solution was then heated in domestic microwave for $30 \mathrm{~s}$, and there was a slight change in color of the solution. The intense brown colored solution was obtained on $1 \mathrm{~min}$ heating with $O$. majorana and $5 \mathrm{~min}$ heating with $C$. sinensis extract. The intense brown color indicated the formation of SNPs (Fig. 2).

\section{Characterization}

The bioreduction of $\mathrm{Ag}^{+}$ion in aqueous solution was monitored with the help of UV-2600 series Shimadzu spectrophotometer. Fourier transform infrared (FT-IR) spectra for plant leaf powder and SNPs were obtained in the range $4000-400 \mathrm{~cm}^{-1}$ with a Shimadzu FT-IR spectrophotometer using $\mathrm{KBr}$ pellet method. Scanning electron microscopy (SEM) analysis coupled with energy dispersive spectroscopy (EDAX) of synthesized SNPs was done using a model-JEOL-5800-LV 16. All TEM images were obtained using a JEOL model 1200 EX instrument with an accelerating voltage of $120 \mathrm{kV}$. TEM samples were prepared by drop casting of nanoparticles dispersion onto carbon-coated copper TEM grid, followed by air drying at ambient conditions. TEM samples were stored in a desiccator and imaged shortly after collection.

\section{Anti-microbial study}

The antibacterial activity of SNPs was carried out on human pathogenic Escherichia coli and Bacillus subtilis by standard disk diffusion method. LB broth/agar medium was used to cultivate bacteria. Fresh overnight inoculum $(100 \mu \mathrm{l})$ of each culture was spread on to LB agar plates. Sterile paper disks of $5 \mathrm{~mm}$ diameter containing various concentrations $(\mu \mathrm{g} / \mathrm{ml})$ of SNPs were placed in each plate. Each plate also contained a disk loaded with standard antibiotic as a reference. The plates containing bacteria and SNPs were incubated at $37^{\circ} \mathrm{C}$. The plates were then examined for zones of inhibition. The clear area around the disk is known as zone of inhibition. The diameters of such zones were measured using meter ruler and expressed in millimeter.

\section{Results and discussions \\ UV-Vis spectral analysis}

The formation of SNPs was analyzed by UV-Visible spectroscopy. Figure $3(\mathrm{a}$ and $\mathrm{b})$ shows the UV-Visible spectra recorded from mixture of aqueous leaf extract (O. majorana and C. sinensis) and Ag salt solution as a function of time of reaction. After microwave heating, the color of the solution changed from colorless to brown. It is wellknown that SNPs exhibit dark brown colors, depending on the intensity and the size of nanoparticles; the colors arise due to the excitation of surface plasmon resonance (SPR) of the SNPs (Mulvaney 1996). The SPR of SNPs was observed at 380 and $420 \mathrm{~nm}$ in O. majoranamediated SNPs which steadily increased in intensity as a function of time of reaction i.e., after $30 \mathrm{~s}$ and $1 \mathrm{~min}$. No further change in the intensity of SPR was observed when the solution was microwaved for 2 and more. This shows that the formation of SNP was completed after $1 \mathrm{~min}$ in

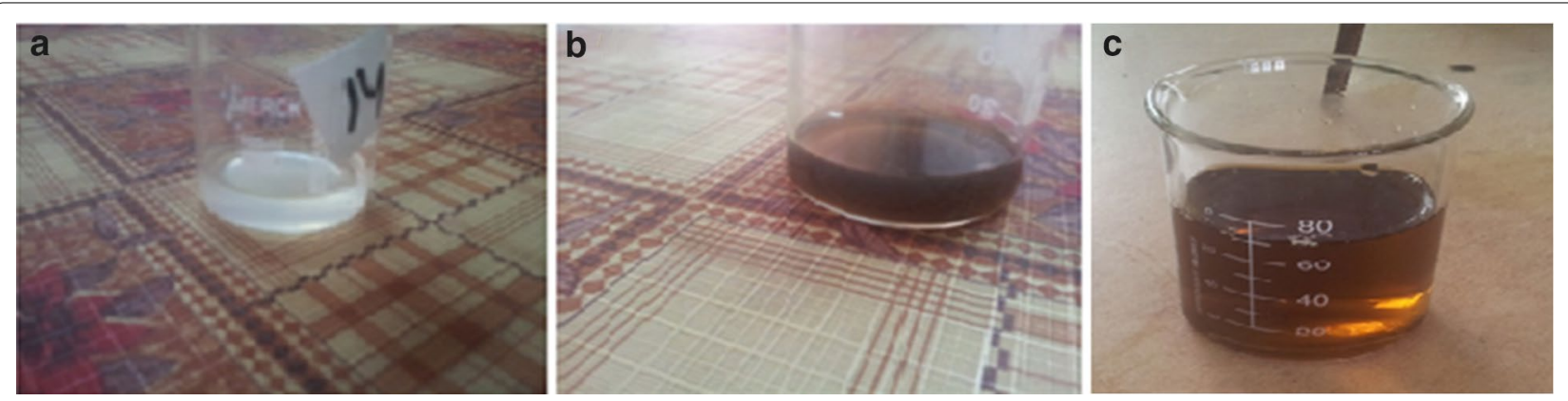

Fig. 2 a $\mathrm{AgNO}_{3}$ solution, silver nanoparticles formed from $\mathbf{b}$ Origanum majorana c Citrus sinensis leaf extract 

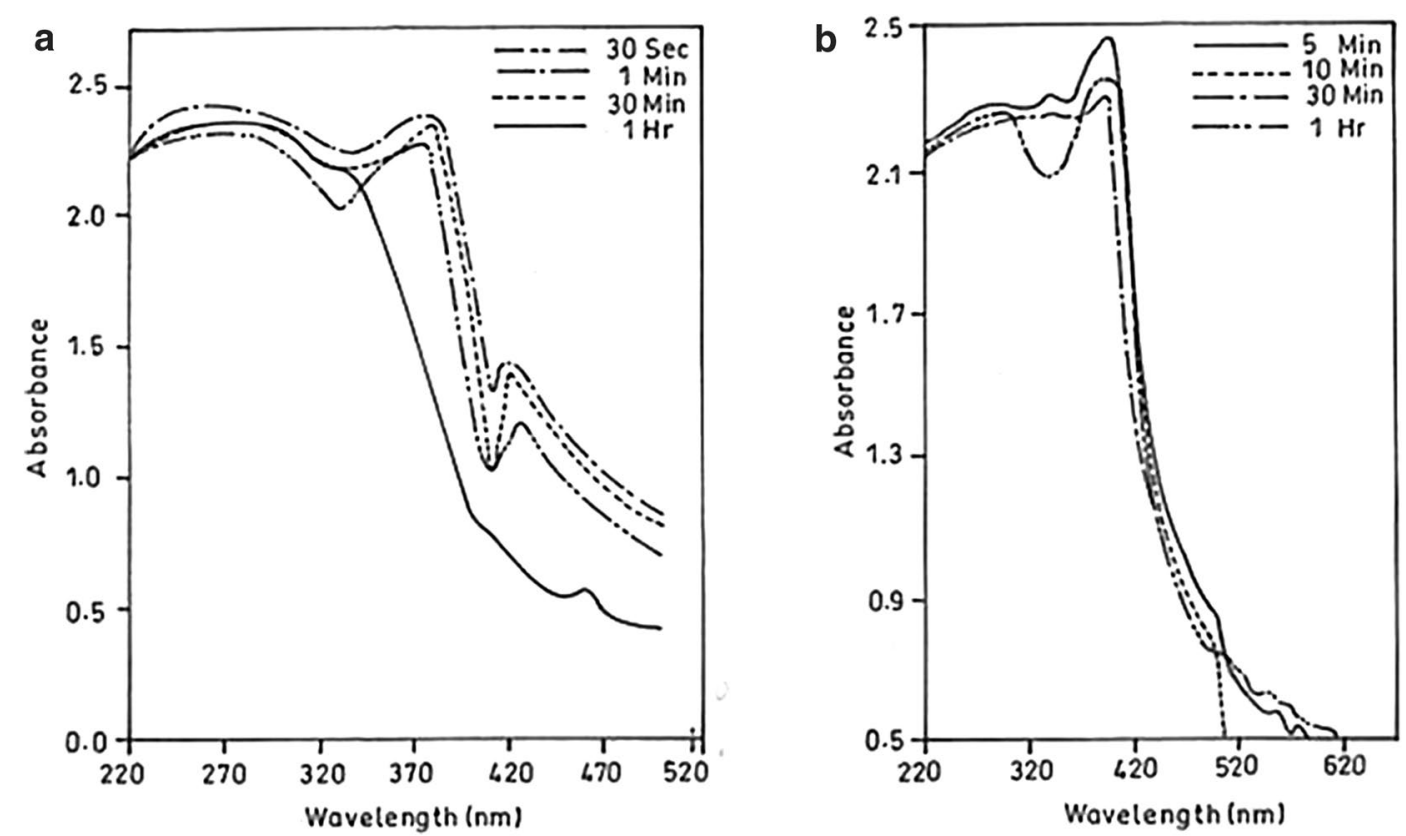

Fig. 3 UV-Vis spectra of silver nanoparticles using a Origanum majorana b Citrus sinensis

case of O. majorana. Whereas SPR for SNPs formed from C. sinensis was obtained at 340 and $410 \mathrm{~nm}$ after $5 \mathrm{~min}$. As we can see that when the mixture of silver salt and $C$. sinensis extract was microwaved for $10,15,20 \mathrm{~min}$, and so on, no further increase in SPR was observed. The peak characteristic of SNPs was decreased after heating for $1 \mathrm{~h}$ which shows the instability of SNPs.
FT-IR

FT-IR spectrum was recorded to find out the functional groups responsible for reduction and stabilization of NPs. The formation of SNPs was confirmed by changes in the bands after synthesis. In Fig. 4a, a broad band around $3368 \mathrm{~cm}^{-1}$ showed the presence of $-\mathrm{OH}$ group. Compared to plant extract, this peak showed a shift to
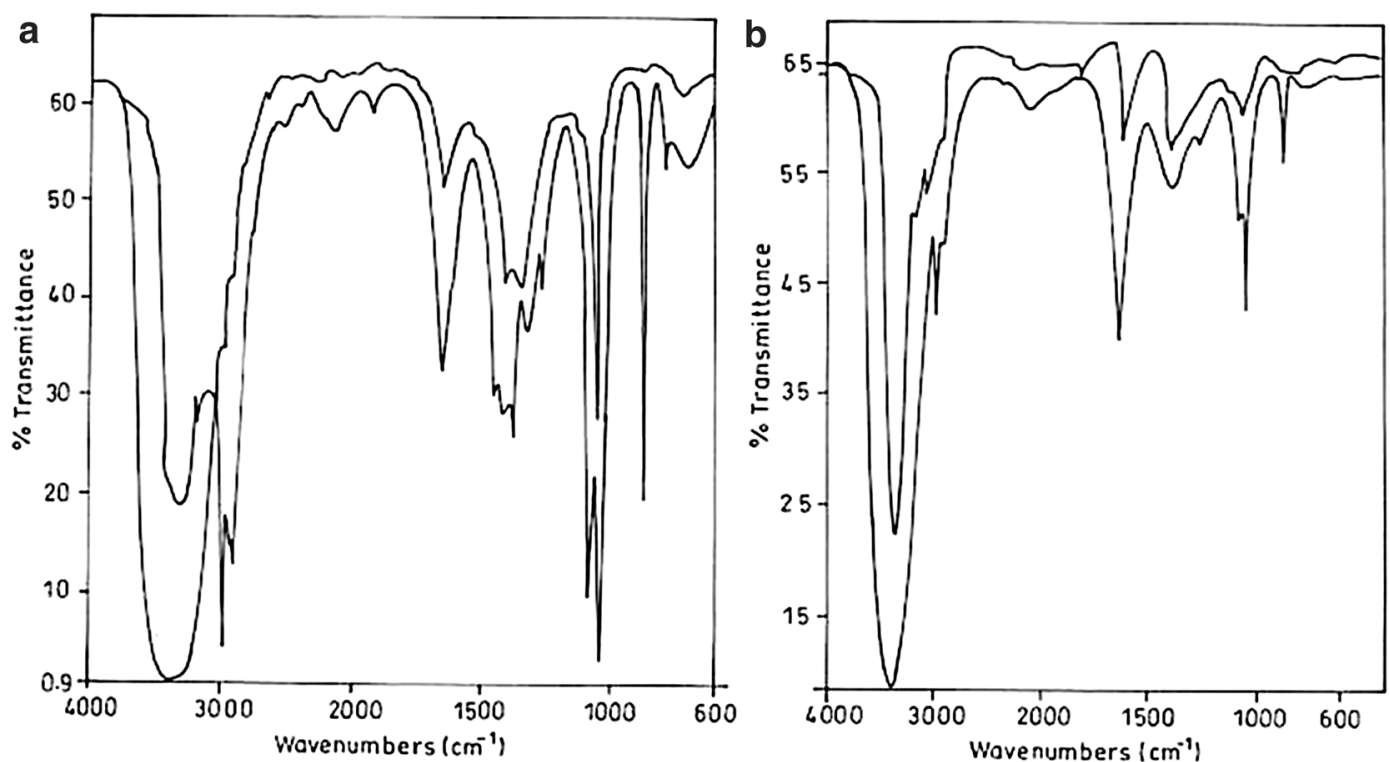

Fig. 4 FT-IR of silver nanoparticles synthesized from $\mathbf{a}$ Origanum majorana $\mathbf{b}$ Citrus sinensis 
lower frequency and a decrease in intensity on binding with the silver. Sharp band was observed at $1654 \mathrm{~cm}^{-1}$ due to the carbonyl group (Shiv Shankar et al. 2003). Peak at $1607 \mathrm{~cm}^{-1}$ showed the presence of amide I vibrations, and this band was shifted in SNPs because of the proteins that possibly bind to SNPs through the amine groups. The peaks at 2844 and $2923 \mathrm{~cm}^{-1}$ represented the symmetric and asymmetric stretching for $\mathrm{C}-\mathrm{H}$ (Nune et al. 2009). In Fig. 4b, broad and intensified peak at $3421.92 \mathrm{~cm}^{-1}$ indicated the $\mathrm{O}-\mathrm{H}$ group stretching of phenolic group present in the orange leaf extract. Sharp peaks at 1642 and $1598 \mathrm{~cm}^{-1}$ were due to $C=C$ stretching, this group must be present in flavonoids and monoterpenes (Awad et al. 2014) and amide group in proteins. Peak at 1085 and
$1047.57 \mathrm{~cm}^{-1}$ indicated $\mathrm{C}-\mathrm{O}$ stretching in primary and secondary alcohols, respectively (Khalil 2014).

\section{SEM-EDAX analysis}

Figure 5 shows the SEM and EDAX images of the $O$. majorana and $C$. sinensis-mediated SNPs. The SEM analysis confirmed the presence of nano-size metal particles. They were spherical and cubical in shape and the diameter of the particle was less than $70 \mathrm{~nm}$. The SEM image of both types of SNPs showed the presence of polydispersed SNPs. The presence of optical peak at $3 \mathrm{keV}$ in EDAX characteristics to metallic silver further confirmed the synthesis of SNPs due to SPR (Kalimuthu et al. 2008).
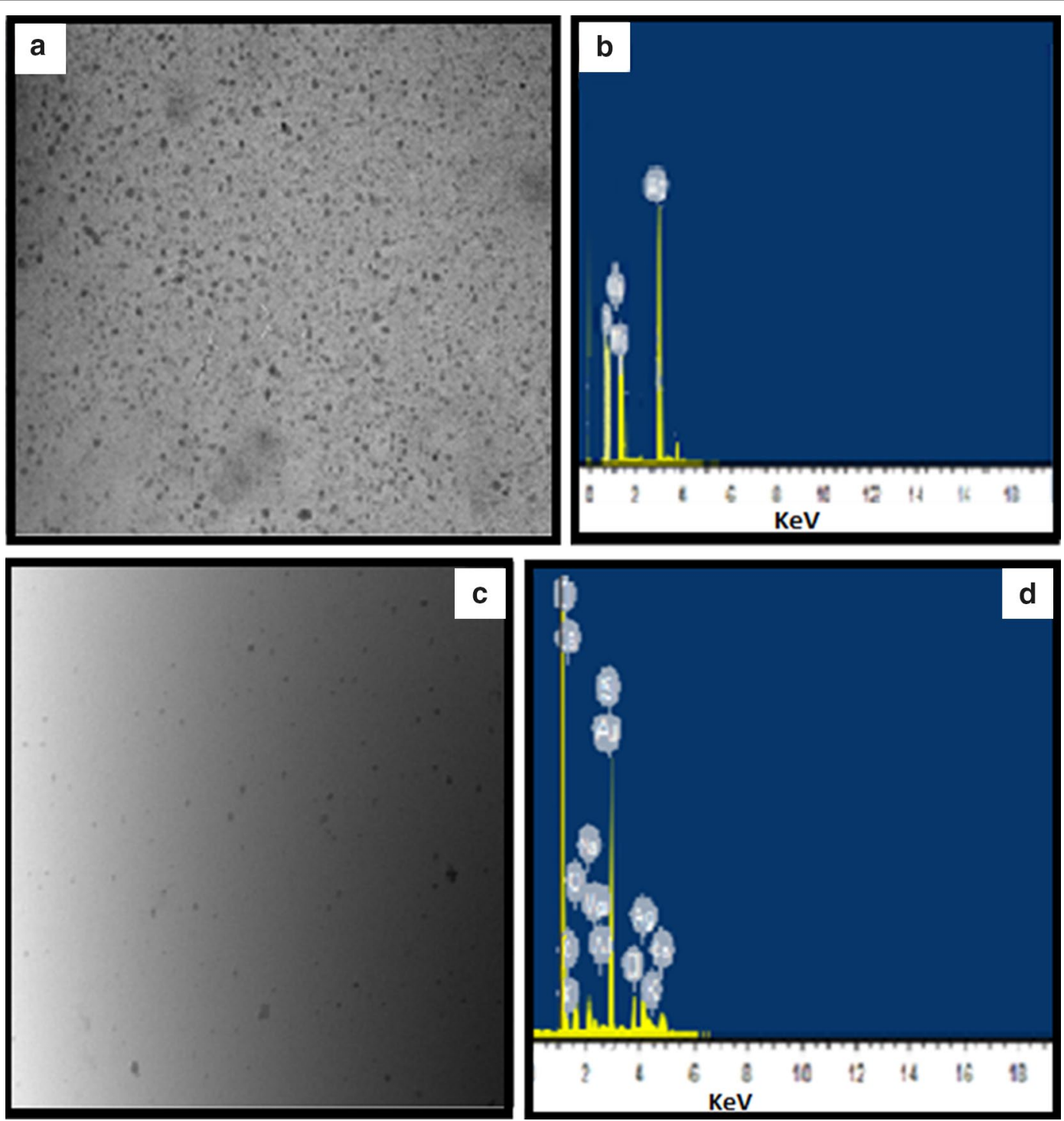

Fig. 5 a SEM b EDAX image of Origanum majorana-mediated SNPS c SEM d EDAX image of Citrus sinensis-mediated SNPs 
High-resolution transmission electron microscopy (HRTEM) Figure 6 shows the TEM images of synthesized SNPs. TEM micrographs of O. majorana-mediated SNPs clearly showed the presence of feather-like shape of nanoparticles. The average diameter of SNPs was found to be in the range of 40-70 nm. The TEM micrographs of C. sinensis-mediated SNPs showed that they were non-uniform in shape, mostly spherical and some were cubical. Particle sizes varying from 22 to $60 \mathrm{~nm}$ can be observed from these images.

\section{Anti-microbial study}

Antibacterial activity of synthesized SNPs was carried out against two bacterial strains namely $E$. coli and $B$. subtilis by disk diffusion method. SNPs showed remarkable activity against all the mentioned pathogenic bacteria. The minimum inhibitory concentration (MIC) values from Table 1 indicates that considerably low amount of SNPs $(25-50 \mu \mathrm{g} / \mathrm{ml})$ was able to kill the bacterial cells.
O. majorana-mediated SNPs showed better result against $E$. coli at the minimum concentration of $25 \mu \mathrm{g} / \mathrm{ml}$, whereas -mediated SNPs were good against B. subtilis. The antibacterial activity of SNPs depends upon the concentration of NPs used. As evident from table, inhibition against bacteria increased with increasing the concentration of SNPs. The nanoparticles bind to the cell membrane and also pierced inside the bacteria. SNPs interact with sulfur present in the proteins as well as with the phosphorus containing compounds like DNA (Morones et al. 2005). When SNPs enter the bacterial cell, it forms a low molecular weight region in the center of the bacteria to which the bacteria conglomerates thus, protecting the DNA from the silver ions. The nanoparticles preferably attack the respiratory chain, cell division finally leading to cell death. The nanoparticles release silver ions in the bacterial cells, which enhance their bactericidal activity (Lok 2006).
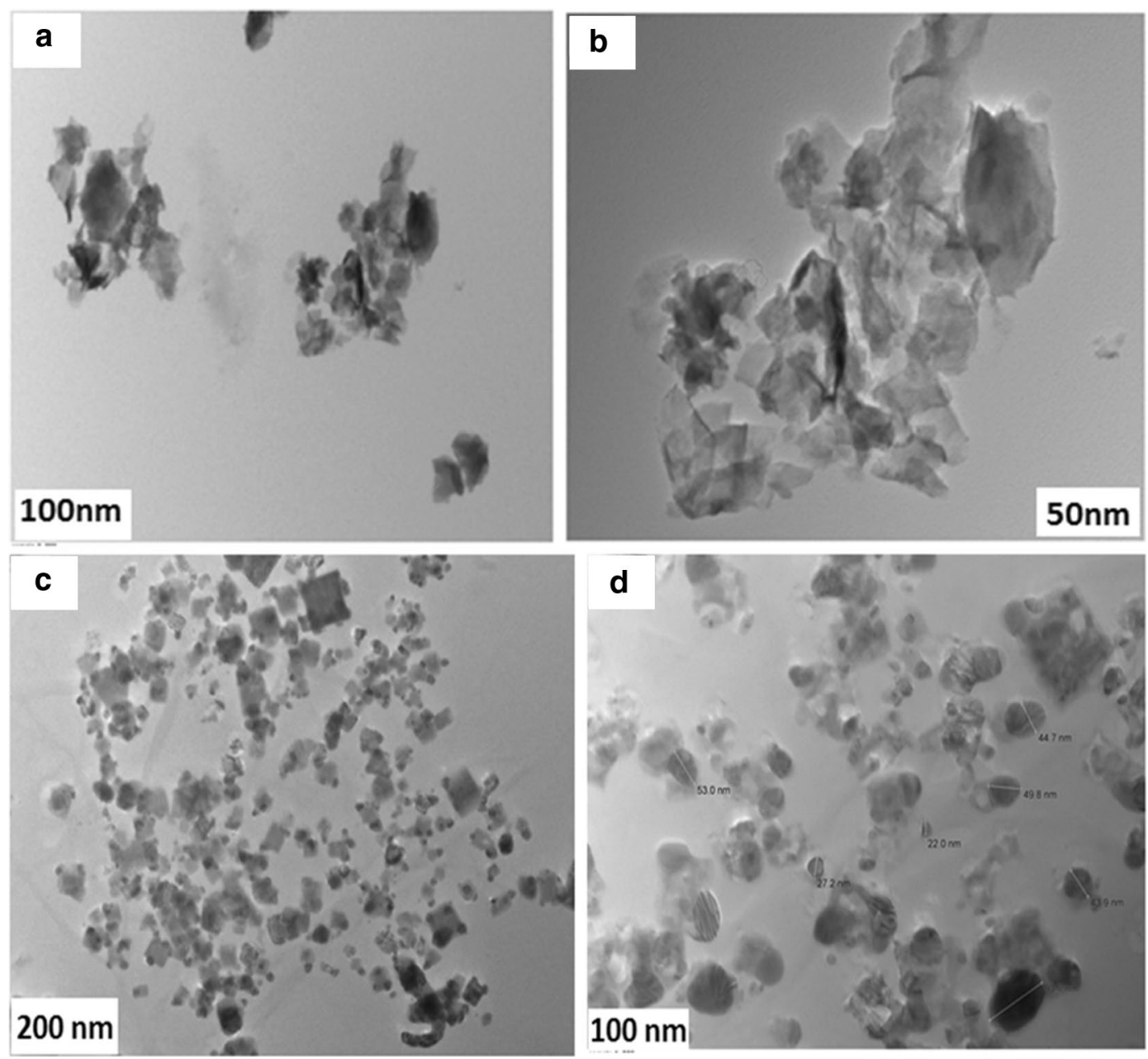

Fig. 6 TEM micrographs of SNPS synthesized by reduction of $\mathrm{Ag}^{+}$ions using $\mathbf{a}$, $\mathbf{b}$ Origanum majorana $\mathbf{c}, \mathbf{d}$ Citrus sinensis leaf extract on various scales 
Table 1 Antibacterial activity of Origanum majorana and Citrus sinensis-mediated SNPs

\begin{tabular}{|c|c|c|c|}
\hline \multirow[t]{2}{*}{ Samples } & \multirow{2}{*}{$\begin{array}{l}\text { Concentration } \\
(\mu \mathrm{g} / \mathrm{ml})\end{array}$} & \multicolumn{2}{|c|}{ Zone of inhibition (mm) } \\
\hline & & $\begin{array}{l}\text { Origanum majo- } \\
\text { rana-mediated } \\
\text { SNPs }\end{array}$ & $\begin{array}{l}\text { Citrus sinensis- } \\
\text { mediated SNPs }\end{array}$ \\
\hline \multirow[t]{3}{*}{ E. coli } & 25 & 11.0 & 8.5 \\
\hline & 50 & 12.0 & 9.0 \\
\hline & 75 & 12.5 & 9.0 \\
\hline \multirow[t]{3}{*}{ Bacillus subtilis } & 25 & Nil & 13.0 \\
\hline & 50 & 7.0 & 17.0 \\
\hline & 75 & 9.0 & 19.0 \\
\hline
\end{tabular}

\section{Conclusions}

The present article reports the biosynthesis of SNPs from $O$. majorana and $C$. sinensis leaf for the first time. $O$. majorana/C. sinensis leaf extract is capable of reduction and stabilization of SNPs. Moreover, microwave radiation and its mode of heating make the synthesis of the metallic nanoparticles fast, uniform, and reproducible. SNPs showed superior antibacterial activity toward E. coli and $B$. subtilis pathogens. It is an environmental friendly process for the production of SNPs and completely free from toxic solvents and chemicals. So, it is one of the effective recycling processes to utilize the O. majorana and C. sinensis for the production SNPs. Therefore, biogenic synthesized SNPs can be used for waste water treatment, food and water storage, and manufacturing medicinal supplies such as beds.

\section{Authors' contributions}

All authors have been involved in the writing and interpretation of results during preparation of the manuscript. All authors read and approved the final manuscript.

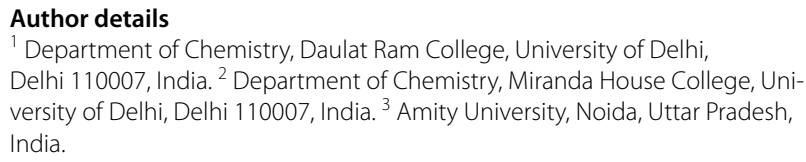

\section{Acknowledgements}

The authors are grateful to the Daulat Ram College, University of Delhi for carrying out experimental work. I express my sincere thanks to the director USIC, University of Delhi, for providing instrumentation technique which is necessary this research work.

\section{Competing interests}

The authors declare that they have no competing interests.
Received: 1 December 2015 Accepted: 2 March 2016

Published online: 16 March 2016

\section{References}

Awad MA, Hendi AA, Ortashi KMO, Elradi DFA, Eisa NE, Al-lahieb LA, Al-Otiby SM, Merghani NM, Awad AAG (2014) Int J Phys Sci 9(3):34

Bae CH, Nam SH, Park SM (2002) Appl Surf Sci 197:628

Bahadur NM, Furusawa T, Sato M, Kurayama F, Siddiquey IA, Suzuki N (2011) J Colloid Interface Sci 355(2):312

Basavaraja S, Balaji DF, Lagashetty A, Rajasab AH, Venkataraman A (2008) Mater Res Bull 43:1164

Catauro M, Raucci MG, De Gaaetano FD, Marotta A (2004) J Mater Sci Mater Med 15(7):831

Crabtree JH, Brruchette RJ, Siddiqi R, Huen IT, Handott LL, Fishman A (2003) Perit Dial Int 23(4):368

Easu SR, Roberto SB, Ocotlan-Flores J, Saniger JM (2010) J Nanopart Res 9:77 Geethalakshmi E, Sarada DV (2010) Int J Eng Sci Tech 2:970

He S, Guo Z, Zhang Y, Zhang S, Wang J, Gu N (2007) Mater Lett 61:3984

Huang J, Li Q, Sun D, Lu Y, Su Y, Yang X (2008) Nanotechnology 18:105104

Jha AK, Prasad K (2010) Inter J Green Nanotechno Phys Chem 1:110

Jiang D, Chen L, Zhu J, Chen M, Shi W, Xie J (2013) Dalton Trans 42(44):15726

Kalimuthu K, Babu RS, Venkataraman D, Bilal M, Gurunathan S (2008) Colloids Surf B Biointerfaces 65:150

Keki S, Torok J, Deak G (2000) J Colloid Interface Sci 229:550

Khalil MMH (2014) Arab J Chem 7:1131

Kowshik M, Ashtaputre S, Kharrazi SS, Vogel W, Urban J, Kulkarni SK, Paknikar M (2003) Nanotechnology 14:95

Krolikowska A, Kudelski A, Michota A (2003) Bukowska. J Surf Sci 532:227

Kumar VS, Nagaraja BM, Shashikala V, Padmasri AH, Madhavendra SS, Raju BD (2004) J Mol Catal A 223:313

Liu YC, Lin LH (2004) Electrochem Commun 6(11):1163

Lok C (2006) J Proteomic Res 5:916

Mandal D, Blonder ME, Mukhopadhyay D, Sankar G, Mukherjea P (2000) Appl Microbiol Biotechnol 69:485

Morones JR, Elechiguerra JC, Camacho A, Holt K, Kouri JB (2005) Nanotechnology 16:2346

Mulvaney P (1996) Langmuir 12:788

Navaladian S, Viswanathan B, Viswanath RP, Varadarajan TK (2007) Nanoscale Res Lett 2:44

Nune SK, Chandra N, Shukla R, Katti K, Kulkarni RR, Thilakavathy S (2009) J Mater Chem 19:2912

Raveendran P, Fu J, Wallen SL (2003a) J Am Chem Soc 125:13940

Raveendran P, Fu J, Wallen SL (2003b) J Am Chem Soc 125:13940

Sanghi R, Verma P (2009) Bioresour Technol 100:501

Sharma VK, Yngard RA, Yekaterina L (2009) Colloid and Interface Sci 145:83

Shiv Shankar S, Ahmad A, Sastry M (2003) Biotechno Prog 19:1627

Singh V, Kumar P, Sanghi R (2012) Prog Polym Sci 37(2):340

Sivakumar P, Nethradevi C, Renganathan S (2012) Asian J Pharm Clin Res 5(3):97

Song JY, Kim BS (2009) Bioprocess Biosyst Eng 32:79

Starowicz M, Stypula B, Banas J (2006) Electrochem Commun 8(2):227

Tanan W, Saengsuwan S (2014) Energy Procedia 56:386

Vorobyova SA, Lesnikovich Al, Sobal NS (1999) Colloid Surf A 152:375

Xin H, Wu H, Liao X, Shi B (2010) Green Chem 12:395

Yu D-G (2007) Colloids Surf B 59:171 